\title{
Acute in vivo studies on glucose absorption from the small intestine of lambs, sheep and rats
}

\author{
By R. G. WHITE*, V. J. WILLIAMS AND R. J. H. MORRIS \\ Department of Physiology, School of Rural Science, \\ University of New England, Armidale, NSW 2351, Australia
}

(Received 27 October 1969-Accepted I 5 fune 1970)

\begin{abstract}
I. Rates of disappearance of glucose from ligated loops of small intestine in lambs, adult sheep and young rats were studied. The concentration of glucose in the lumen decreased exponentially with time, suggesting that within a range of concentrations of $166-277 \mathrm{~m}-\mathrm{moles} / \mathrm{l}$ glucose was absorbed mainly by passive diffusion.

2. The rate of absorption of glucose from a $166 \mathrm{~mm}$-solution based on either zero or first order kinetics and expressed as $\mathrm{m}$-moles/m small intestine per $\mathrm{h}$ decreased along the intestine from the duodenum to the ileum in lambs and rats. The decrease was slight in adult sheep.

3. The total absorptive capacity of the small intestine of adult grazing sheep for glucose from $166 \mathrm{~mm}$-solutions $(0.6 \mathrm{~m}$-moles $/ \mathrm{kg}$ body-weight per $\mathrm{h}$ ) was approximately $25 \%$ of that for lambs less than $I$ week of age.

4. Young rats had a greater absorptive capacity of the small intestine (12.9 m-moles/kg body-weight per $\mathrm{h}$ ) than adult sheep of about $40 \mathrm{~kg}$ body-weight $(0.6 \mathrm{~m}$-moles $/ \mathrm{kg}$ body-weight per $h$ ) and this largely reflected a longer small intestine per unit body-weight.

5. The absorptive capacity of lambs for glucose was greater when the level of voluntary lactose intake was increased before an experiment. The absorptive capacity of the ileum of adult sheep given wheat was greater than that of grazing adult sheep.

6. Developmental changes in glucose absorption are discussed in relation to normal changes in diet and to changes in the morphology of the small intestine with age.
\end{abstract}

Heald (I95I), McClymont \& Scarisbrick (quoted by McClymont, I95I), Schambye (195 I $a, b)$ and Weller \& Gray (1954) have shown that little glucose is absorbed from the small intestines of sheep fed on only roughage. In sheep given rations high in grain, starch enters and is hydrolysed in the small intestine. The amount of starch available for hydrolysis appears to be variable. MacRae \& Armstrong (I966) reported that only between 16.8 and $21.9 \mathrm{~g} / \mathrm{d}$ of $\alpha$-linked polymers of glucose entered the small intestine of sheep fed on $200 \mathrm{~g}$ hay plus $700 \mathrm{~g}$ rolled barley, and similar results have been obtained for sheep given flaked maize (Nicholson \& Sutton, 1969; Ørskov, Frazer \& Kay, 1969). In the latter experiments there was incomplete digestion of starch in the small intestine and these authors suggest that the small intestine has only a limited capacity for starch digestion.

Lambs younger than 3 weeks absorb glucose and galactose in amounts proportional to the quantity of lactose hydrolysed. Lactose intake, calculated from the milk production of grazing ewes (Davies, 1963 ) and a lactose concentration of $5 \mathrm{~g} / 100 \mathrm{ml} \mathrm{milk}$ (Corbett, $\mathrm{Ig} 68$ ), is at a maximum of about $60 \mathrm{~g} / \mathrm{d}$ at 2-4 weeks of age and declines to approximately $30 \mathrm{~g}$ at 8-9 weeks of age. In Australia, after Io weeks of age, lambs are generally weaned on to roughage, and glucose absorption would then be small.

In the study now reported, changes with age in the rate of glucose absorption from glucose solutions in loops of small intestine were investigated in anaesthetized lambs

\footnotetext{
* Present address: Institute of Arctic Biology, University of Alaska, College, Alaska 9970r, USA.
} 
and sheep. The ability of the small intestine of lambs to absorb glucose, and the effect on glucose absorption of feeding above-normal levels of lactose to lambs from 4 to 17 weeks of age, were also studied.

\section{EXPERIMENTAL}

\section{Experimental animals and preliminary feeding regimens}

Merino sheep and lambs and albino rats were used. The animals were subjected to the following regimens before absorption experiments.

\section{Sheep grazing on mixed white clover and grass pasture}

Group $L P$. The subjects were lambs at pasture taken from their mothers $2-3 \mathrm{~h}$ before an experiment. They ranged in age from birth to $100 \mathrm{~d}$.

Group LI. The subjects were lambs at pasture with their mothers and separated from them $16 \mathrm{~h}$ before an experiment. Water was available at all times. They were grouped as follows: $\mathrm{LI} a$, three lambs between 2 and $7 \mathrm{~d}$ of age; $\mathrm{LI} b$, three lambs $2 \mathrm{I}$ or $22 \mathrm{~d}$ of age; $\mathrm{LI} c$, three lambs between 5 and $\mathrm{I} 7$ weeks of age.

Group $A I$. The subjects were adult sheep, two wethers and one ewe, grazing with ewes and lambs of group LI. They were taken from pasture $\mathrm{I} 6 \mathrm{~h}$ before each experiment and were allowed free access to water during that time.

\section{Lambs reared on a reconstituted milk diet}

Group LII. This group consisted of five lambs between 5 and 17 weeks of age. They were taken from their mothers at $3 \mathrm{~d}$ of age and were fed three times daily at $08.00,13.00$ and 18.00 hours until $21 \mathrm{~d}$ of age, after which they were fed twice daily at 09.00 and 16.00 hours. The last feed was given $16 \mathrm{~h}$ before an experiment.

The whole-milk powder had the following composition. Major chemicals (\%): lactose 37.3 , crude protein 27.5 , fat $26 \cdot 2$, water 3.0 ; minerals (\%): $\mathrm{P} 0.75, \mathrm{Na} 0.40$, $\mathrm{K}$ I.20, $\mathrm{Ca} 0.97, \mathrm{Mg} 0.1, \mathrm{~S} 0.2, \mathrm{Cl} 0.8, \mathrm{Fe} 0.006$; vitamins (per kg): retinol $3.3 \mathrm{mg}$, riboflavin $14.8 \mathrm{mg}$, thiamin $2.6 \mathrm{mg}$, pyridoxine $3.3 \mathrm{mg}$, cyanocobalamin $19.8 \mu \mathrm{g}$, biotin $0.4 \mathrm{mg}$, choline $880.0 \mathrm{mg}$, pteroylmonoglutamic acid $19.8 \mu \mathrm{g}$, pantothenic acid $28 \cdot 5 \mathrm{mg}$; energy (kcal $/ \mathrm{kg}) 4980$.

Adult sheep fed in pens on $100 \mathrm{~g}$ lucerne chaff plus $500 \mathrm{~g}$ whole wheat grain

Group AII. Three adult ewes fed once daily at 09.00 hours for a period of at least 6 weeks were used. They were not fed on the day of the experiment but were allowed free access to water.

\section{Young albino rats fed ad lib. on rat cubes}

Six female rats, in two groups of three, of 8-9 weeks of age, were used. They were without food, but allowed water, for $16 \mathrm{~h}$ before an experiment.

The food cubes had the following composition. Gross constituents (\%): wheatmeal 54 , coconut 6 , meat meal 19.5 , milk powder 8 , yeast $\mathrm{I}$, bone flour $\mathrm{I}$, lucerne 10 , salt 0.5 ; major chemicals (\%): crude protein 20 , crude fat 7.5 , Ca $2.5, \mathrm{P}_{1} \cdot 3$; vitamins (per $\mathrm{kg}$ ): cholecalciferol $0.055 \mathrm{mg}$, vitamin E $20.0 \mathrm{mg}$, retinol $2.6 \mathrm{mg}$. 


\section{Test solutions}

\section{Experimental procedures}

For most experiments a $166 \mathrm{~mm}$-glucose solution was made up in a sodium phosphate buffer $\left(43 \cdot 3 \mathrm{~mm}-\mathrm{Na}_{2} \mathrm{HPO}_{4}\right.$ plus $\left.18 \cdot 2 \mathrm{mM}-\mathrm{NaH}_{2} \mathrm{PO}_{4}\right)$ with a $\mathrm{pH}$ between $7 \cdot \mathrm{I}_{5}$ and $7 \cdot 20$ and a total osmolarity of $310 \mathrm{mOsm} / \mathrm{l}$. In other experiments in which glucose solutions less than I $66 \mathrm{~mm}$ were used, the solutions contained the same buffer but the osmotic pressure was adjusted to $310 \mathrm{mOsm} / 1$ by the addition of $\mathrm{NaCl}$. When a $277 \mathrm{mM}$ solution was required, the buffer was diluted appropriately before adding the glucose to effect isotonicity.

\section{Anaesthesia, formation of loops, loop filling and solution recovery}

In lambs and sheep, anaesthesia was induced by intravenous injections of pentobarbitone sodium (crystalline powder; May \& Baker, Dagenham, Essex) in $\mathrm{NaCl}$ solution. The level was insufficient to abolish the reflex flexion of the limbs in response to pressure between the toes. Rats were injected intraperitoneally with a dose of $5 \mathrm{mg} / \mathrm{roO} \mathrm{g}$ body-weight of pentobarbitone sodium in $0.9 \%(\mathrm{w} / \mathrm{v}) \mathrm{NaCl}$. A glass cannula was inserted into the trachea of each animal.

Sheep and lambs were laid on their left sides and the abdominal cavities were entered by incisions which extended from near the point of attachment of the last rib to within $16 \mathrm{~cm}$ of the ventral mid line and passing about $10 \mathrm{~cm}$ from the right leg. Two regions were located and marked with cotton thread and small numbered plaques. One was as close as possible to the pylorus and the other about $\mathrm{I} \mathrm{m}$ from the ileocaecal junction. A third region was chosen approximately mid way between the other two. Portions of $10-15 \mathrm{ml}$ of $0.9 \%(\mathrm{w} / \mathrm{v}) \mathrm{NaCl}$ solution at $37^{\circ}$ were then injected into the lumen of the intestine in each region through a $16 \mathrm{G}$ hypodermic needle. The saline was moved down the lumen by gentle manipulation with a thumb and forefinger to wash about $60 \mathrm{~cm}$ free of digesta. Three groups of three loops, each about $20 \mathrm{~cm}$ long, were formed in the washed regions by double ligation at four points.

Known quantities of about $30 \mathrm{ml}$ of test solution at $37^{\circ}$ were injected into the lumen of the outer two loops of each group at timed intervals and puncture wounds were tied with cotton thread. The middle loop of each group was filled with saline at $37^{\circ}$ by the same procedure. The volume of solution injected was sufficient to expand the intestine evenly without undue stretching. After each group of loops had been filled with the test solutions they were returned to the abdominal cavity and the incision was closed with clamps.

In some experiments polyethylene catheters were inserted into each loop. They were used either to sample the test fluids at various times, or to fill the loops with test fluids at different intervals without having to remove them from the body cavity for this purpose.

In rats, single abdominal incisions were made from the xiphoid cartilage to the pelvic region. No more than three loops of suitable length could be made. The middle loop was then filled with saline and the other two with a test solution.

At the completion of a test period each animal was killed with an overdose of 
pentobarbitone sodium. The intestinal loops were carefully and quickly dissected from the mesentery. The procedure took between 3 and $7 \mathrm{~min}$. The serosal surface of each loop was washed quickly with saline to remove blood and the loop was blotted on a damp cloth to remove the saline. The volume and $\mathrm{pH}$ of the lumen contents were recorded. Each lumen was then washed with two $3 \mathrm{ml}$ portions of saline. The wash fluids were added to the test solution and the final volume of test solution plus washings was recorded. Recovery of test and control fluids and the washing of the nine loops took about $18 \mathrm{~min}$.

\section{Loop location and length of small intestine}

The lengths of the experimental loops were measured while they lay on a tray. They were dried to constant weight at $96^{\circ}$.

After the test solutions were recovered from the loops, the remainder of the small intestine was detached from the mesentery of the animal. The intestine obtained from sheep was measured by allowing successive lengths to hang vertically under their own weight against a metre rule. Little intestine was left after removing the loops from rats, and these pieces were measured after placing them on a tray. An estimate of the total length of the small intestine was then made and the distance of the centre of each experimental loop from the pylorus was ascertained.

To test the reproducibility of the measurements of short (up to $50 \mathrm{~cm}$ ) and long (greater than $50 \mathrm{~cm}$ ) pieces of intestine, lengths were measured ten times. The coefficients of variation of the mean estimates for short and long pieces were $\mathrm{r} \cdot 4 \mathrm{I}$ and $0.61 \%$ respectively.

\section{Chemical methods}

Test solutions were deproteinized with $0.3 \mathrm{~N}$-perchloric acid and the protein-free solution was diluted appropriately for determination of glucose by the method of Hugget \& Nixon (1956). $\mathrm{pH}$ was determined with a Radiometer $\mathrm{pH}$ meter 22, fitted with glass and calomel electrodes.

Osmotic pressure was measured with a Fiske Osmometer G 62 .

\section{Analysis of results}

Disappearance of glucose (absorption) from intestinal loops was calculated on the assumption that glucose was absorbed by passive diffusion, i.e. by first order kinetics. If first order kinetics hold throughout an absorption period, the glucose concentration, corrected for water flux $\left(C_{r}, \mathrm{~m}\right.$-moles/l) at any time $(t, \mathrm{~min})$ would be given by

$$
C_{r}=C_{0} e^{-k t},
$$

where $C_{0}$ is the initial concentration of glucose (m-moles/1), and $k$ is the rate constant $\left(\mathrm{min}^{-1}\right)$. The glucose concentrations obtained by analysis of the recovered test solutions were multiplied by the factor volume out/volume in to obtain $C_{r}$. The rate constant was estimated by rearrangement of this equation:

$$
k=\left(\log _{e} C_{0}-\log _{e} C_{r}\right) / t .
$$


$k$ was used to calculate the amount of glucose absorbed per unit length of small intestine hourly $(A, \mathrm{~m}$-moles/m.h):

$$
A=\left(60 . I_{0} \cdot k\right) / L,
$$

where $I_{0}$ is the amount of glucose injected into the loop of small intestine (m-moles) and $L$ is the length of the loop (m).

Glucose absorption was also estimated on the assumption that the rate of glucose absorption was constant throughout the absorption period and therefore the rate of absorption of glucose would be independent of concentration, i.e. zero order kinetics. Assuming zero order kinetics hold throughout an absorption period, the absorption rate $\left(A^{\prime}, \mathrm{m}\right.$-moles $\left./ \mathrm{m} . \mathrm{h}\right)$ would be given by

$$
A^{\prime}=\left(I_{0}-I_{r}\right) \times 60 / t . L,
$$

where $I_{0}$ is the amount of glucose injected into the loop and $I_{r}$ is the amount of glucose recovered (m-moles), $t$ is the absorption period ( $\mathrm{min}$ ) and $L$ is the length of loop of small intestine $(\mathrm{m})$.

Values for the rate of absorption of glucose in lambs of various ages were pooled according to age, group and treatment.

Polynomial regression equations relating rate of glucose absorption within each subgroup with the distance of the centre of the loop from the pylorus, or with this distance expressed as a fraction of the total length of small intestine, were calculated. Polynomials were of the form:

$$
y=a+b x+c x^{2}+d x^{3},
$$

where $y$ is the rate of absorption, $x$ is the distance of the mid-point of the loop from the pylorus or the fractional distance from the pylorus, $a$ is the intercept constant and $b, c$ and $d$ are regression coefficients. Only those regression coefficients which were significant $(P<0.05)$ were retained. Polynomials were fitted by computer (IBMI620B). Differences between curves were tested by analysis of covariance (Snedecor, I956).

\section{RESULTS}

\section{Changes in length and dry weight of small intestine with body-weight}

The relationship between small intestine length and body-weight is shown in Fig. I. The intestine achieved its mature length at a body-weight of $17 \mathrm{~kg}$.

A similar relationship was found between dry weight of small intestine and bodyweight. The dry weight of small intestine of the youngest lambs, of from 4 to $8 \mathrm{~kg}$ body-weight, was between 10 and $20 \mathrm{~g}$ and it increased linearly to a mature weight of $80 \mathrm{~g}$ in lambs of $60 \mathrm{~d}$ of age weighing $\mathrm{I} 7 \mathrm{~kg}$ or more. The dry weight ( $\pm \mathrm{SEM}$ ) of small intestine of the adult sheep given wheat plus lucerne chaff (group AII, 69.5 $\pm 6 \cdot 8 \mathrm{~g}$ ) was less than that of the grazing adult sheep (group AI, $83 \cdot 4 \pm 6 \cdot 2 \mathrm{~g}$ ) but the difference was not significant. In all lambs given the reconstituted-milk diet, except one, the dry weight of intestine was the same as that expected in grazing lambs of the same weight. The dry weight of intestine of the odd lamb was $25 \%$ less than that of other lambs in its group.

Dry weight of small intestine per $\mathrm{m}$ was distributed evenly along sheep intestine 
except in groups LI $b$ and LII. In group LI $b$ the weight per unit length of the jejunum was significantly greater than that of the ileum. In group LII, the lambs given reconstituted milk, intestinal dry matter per unit length was greatest in the mid-region of the intestine.

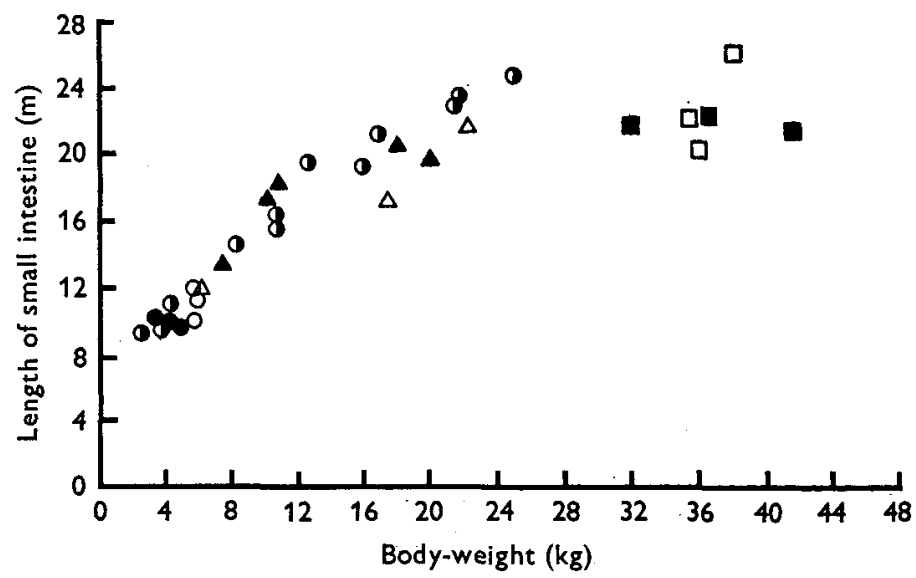

Fig. I. Relationship between length of small intestine and body-weight of sheep and lambs. , group LP; , group LI $a$; O, group LI $b ; \Delta$, group LI $c$; $\triangle$, group LIII.

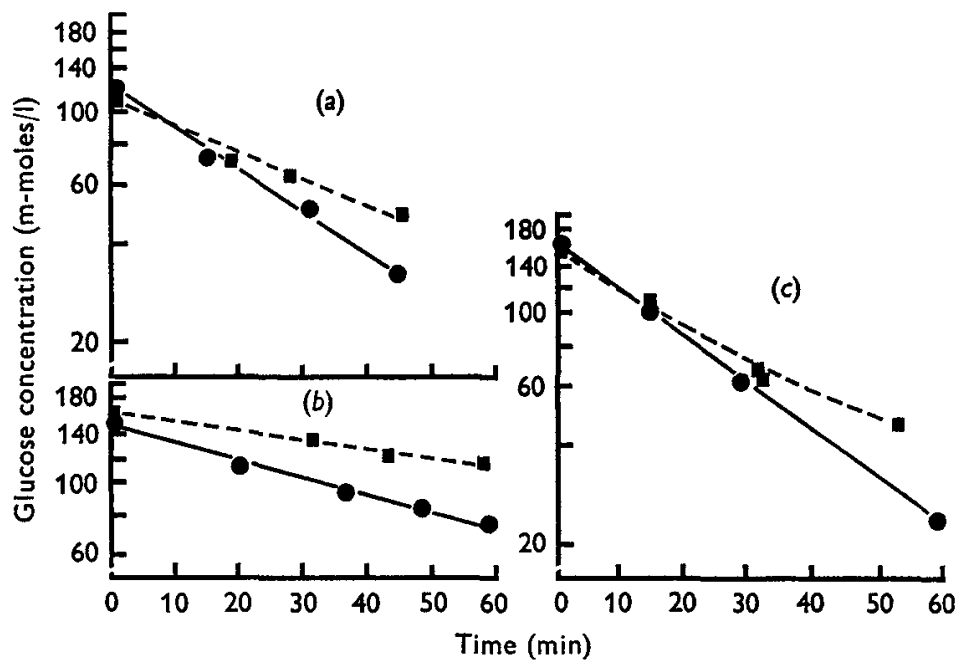

Fig. 2. Changes in glucose concentration of lumen fluid during the absorption period. In $a$ and $b$ lumen fluid was sampled periodically through an in-dwelling catheter; in $c$ the lumen solution was obtained from adjacent loops of intestine. $a$, two loops in a 3-week-old lamb

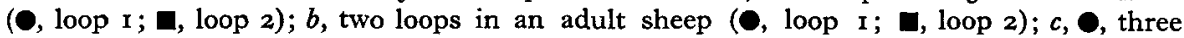
separate loops in a 3-week-old lamb; $\mathbf{n}$, four separate loops in another 3-week-old lamb.

\section{Effect of concentration on the rate of glucose absorption}

In group LP the rate of glucose absorption increased with concentration between 83 and $277 \mathrm{~m}$-moles/l. Two factors precluded measurement of the relationship between concentration and rate of absorption. One was a lowered buffering capacity of the $277 \mathrm{~mm}$-solution, and the other was the non-uniformity in the placement of loops 
with respect to the pylorus; therefore, results were confounded with possible trends in the rate of glucose absorption with distance from the pylorus.

The change in concentration of glucose with time in the lumen solutions sampled through polyethylene catheters is shown in Fig. $2 a$ and $b$. The decrease in glucose concentrations with time was also studied by comparing the final concentration of glucose in several adjacent loops which were filled with test solutions at various time intervals before the test was terminated (Fig. $2 c$ ). Fig. $2 c$ shows that glucose concentration decreased exponentially with time in all except one instance (broken line).

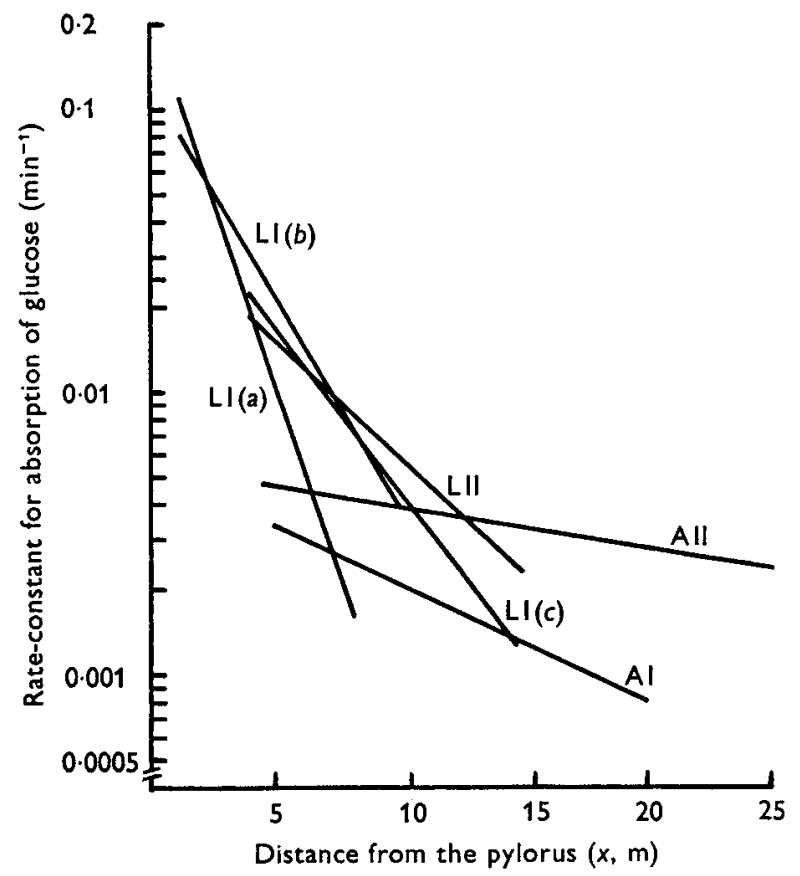

Fig. 3. Rate-constants $\left(k, \mathrm{~min}^{-1}\right)$ of the glucose absorption process in sheep and lambs plotted semi-logarithmically against distance of the mid-point of the site of absorption from the pylorus $(x, \mathrm{~m})$.

$\begin{array}{lcccc}\text { Group } & \text { Equation } & \begin{array}{c}\text { No. of } \\ \text { observations }\end{array} & \begin{array}{c}\text { SE regression } \\ \text { coefficient }\end{array} & \begin{array}{c}\text { Correlation } \\ \text { coefficient }\end{array} \\ \text { LI } a & k=0.2240 e^{-0.367 x} & \text { I6 } & \pm 0.0537 * * & 0.877 \\ \text { LI } b & k=0.1230 e^{-0.842 x} & \text { I6 } & \pm 0.048 I^{* * *} & 0.885 \\ \text { LI } c & k=0.0166 e^{-0.178 x} & \text { I5 } & \pm 0.0389 * * & 0.785 \\ \text { A I } & k=0.0054 e^{-0.095 x} & 17 & \pm 0.0378 * & 0.544 \\ \text { AII } & k=0.0053 e^{-0.031 x} & \text { I5 } & \pm 0.0270 \mathrm{NS} & 0.303 \\ \text { LII } & k=0.0390 e^{-0.183 x} & \text { I8 } & \pm 0.0260 * * * & 0.869 \\ \text { NS, not significant; } * P<0.05 ; * * P<0.01 ; * * * P<0.001 .\end{array}$

In both comparisons the gradient of the line relating the logarithm of the concentration with time (the rate-constant) was greater for 3 -week-old lambs (Fig. $2 a$ ) than for adult sheep (Fig. $2 b$ ). The rate of glucose absorption was, therefore, faster in the lambs.

In lambs of 3 weeks of age and younger the rate-constants for glucose absorption 
were closely related to the distance from the pylorus (Fig. 3). In older lambs and adult sheep the relationship was not as close. Fig. 3 shows that, in general, the slope of the regression line decreased with age. The rate-constants obtained for lambs given the reconstituted milk diet (group LII) were greater than those for normal lambs of the same age (group $\mathrm{LI} c$ ). However, the rate of change in rate-constants, i.e. the regression coefficients, of groups LI $c$ and LII were not significantly different from each other.

\section{Effect of loop position, diet and age on the rate of glucose absorption}

The rate of glucose absorption, based on first order kinetics and expressed as $\mathrm{m}$-moles/m intestine per $\mathrm{h}$, decreased with distance of the loop from the pylorus in all the sheep except those in the group given the diet of wheat plus lucerne chaff (Fig. ${ }_{4} \mathrm{D}$ ). The rumen in adult sheep prevented the preparation of loops in the duodenum and proximal jejunum, which make up approximately $15 \%$ of the total small intestine. Therefore the loops prepared in this region in lambs were not included in Fig. $4 \mathrm{D}$ or in the regression analysis.

In lambs given the reconstituted milk diet (group LII) rates of absorption of glucose at any particular part of the intestine were much greater than in any other group.

The variation in length of small intestine greatly influenced the magnitude of the variance of the regression lines in Fig. $4 \mathrm{D}$ and the heterogeneity precluded the possibility of making statistical comparisons between the group regression lines for lambs and adult sheep. Homogeneity of variance was achieved by relating glucose absorption to the fractional distance of loops from the pylorus instead of to distance from the pylorus (Fig. $4 \mathrm{~F}$ ).

In all the groups except AII the rate of absorption of glucose was related rectilinearly to the relative distance from the pylorus. However, the regression line for group L I $a$ was affected by biased sampling and intersected the $x$ axis at 0.86 . The bias was due to the fact that very few loops were placed in the distal $30 \%$ of the intestine relative to those in the more proximal parts. Experimental observations at about a fractional distance of 0.86 indicated a rate of absorption of glucose of about $0.25 \mathrm{~m}$-moles $/ \mathrm{m} . \mathrm{h}$, not a negligible rate. A second order polynomial was found graphically to fit the results over the whole sampling range; this is the line shown for groups LIa in Fig. ${ }_{4} \mathrm{~F}$.

Covariance analysis indicated that the line L II (lambs given reconstituted milk) was significantly different from LIb (3-week-old lambs) in elevation and LIc (lambs $5^{-1} 7$ weeks old) in both slope and elevation. Although the elevation of the group A I regression line was not significantly different from $\mathrm{LI} b$ and $\mathrm{LI} c$ which were homogeneous with respect to slope and elevation, the differences in regression coefficients were significant $(P<0.05)$. The lines for the two adult groups (AI and A II) were significantly different in elevation $(P<0.01)$ and very highly significantly different in slope $(P<0.001)$. 

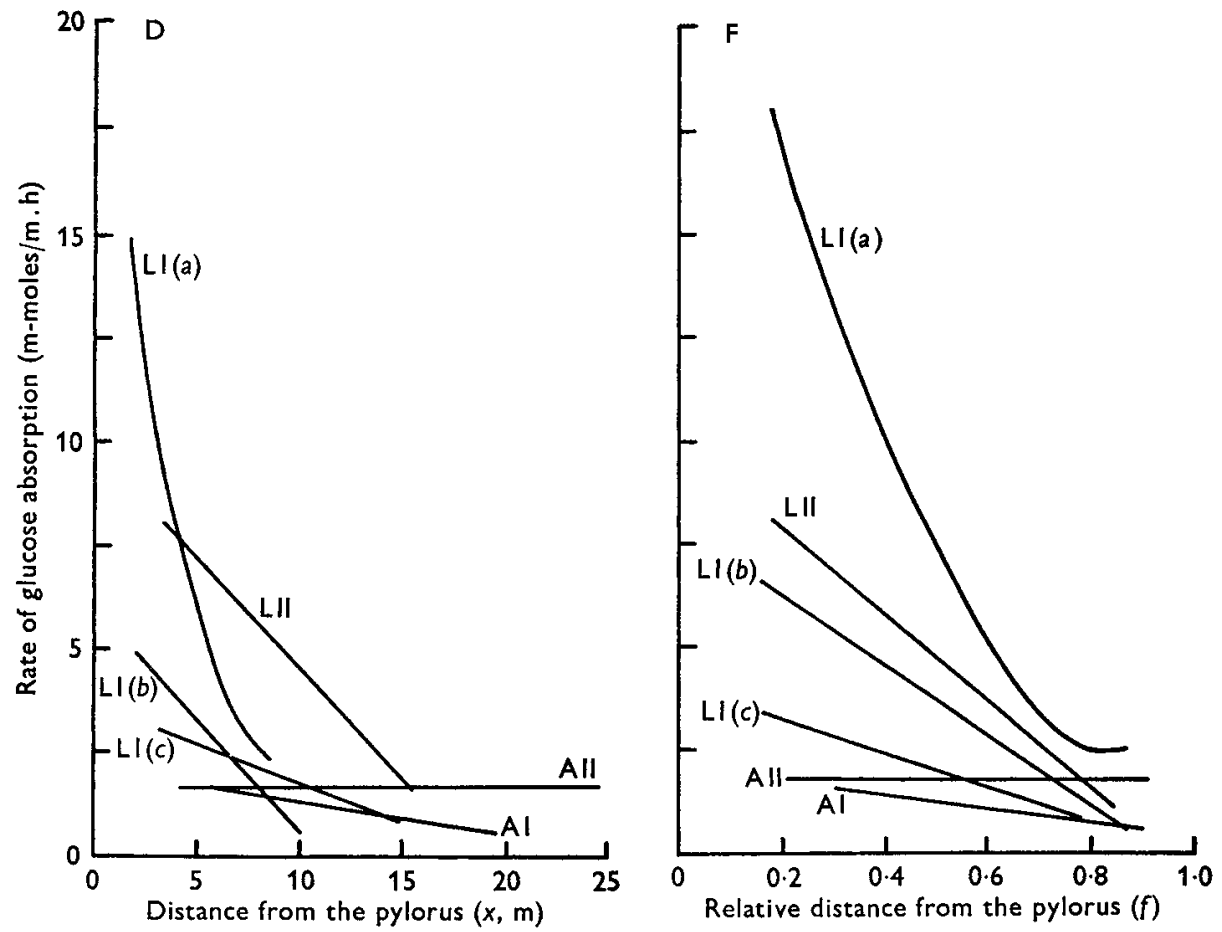

Fig. 4. Regression lines relating rate of glucose absorption (A, m-moles $/ \mathrm{m} . \mathrm{h}$ ) based on first order kinetics with $x$, the distance of the mid-point of the loop from the pylorus in $\mathrm{m}$ (Fig. D; equations $\mathrm{D}$ ) and with $f$, the distance of the mid-point of the loop from the pylorus expressed as a fraction of the total length of the small intestine (Fig. F; equations F).

\begin{tabular}{|c|c|c|c|c|c|c|}
\hline Group & $\begin{array}{l}\text { No. of } \\
\text { observa- } \\
\text { tions }\end{array}$ & $\begin{array}{l}\text { Mean } \\
\text { rate } \\
\text { m-moles/ } \\
\mathrm{m} . \mathrm{h})\end{array}$ & Equations D & $\begin{array}{c}\text { Residual } \\
\text { standard } \\
\text { deviation } \\
\text { of equations D }\end{array}$ & Equations $F$ & $\begin{array}{r}\text { Residual } \\
\text { standard } \\
\text { deviation } \\
\text { equations }\end{array}$ \\
\hline $\mathrm{LI} a$ & 16 & $8 \cdot 87$ & $\begin{aligned} A= & 21 \cdot 61-4.91 x \\
& +0.268 x^{2} \\
& ( \pm 1 \cdot 279)^{* * *} \\
& ( \pm 0.109)^{*}\end{aligned}$ & $I \cdot 22$ & $\begin{aligned} A= & 28.49-59.87 f \\
& +34.12 f^{2} \\
& ( \pm 25.60)^{*} \\
& ( \pm 24.45) \mathrm{NS}\end{aligned}$ & 4.05 \\
\hline $\mathrm{LI} b$ & 16 & $3 \cdot 66$ & $\begin{aligned} A= & 7.36-0.683 x \\
& ( \pm 0.124)^{* * * *}\end{aligned}$ & $I \cdot 04$ & $\begin{aligned} A= & 7 \cdot 93-8 \cdot 443 f \\
& ( \pm \mathrm{I} \cdot 988)^{* * *}\end{aligned}$ & $\mathrm{I} \cdot 85$ \\
\hline $\mathrm{LI} c$ & 15 & $\mathrm{x} \cdot 88$ & $\begin{aligned} A= & 3.68-0.202 x \\
& ( \pm 0.059)^{* *}\end{aligned}$ & 0.85 & $\begin{aligned} A= & 4.06-4.247 f \\
& ( \pm 0.745)^{* * *}\end{aligned}$ & 0.61 \\
\hline A I & 17 & 0.99 & $\begin{aligned} A= & 2.07-0.080 x \\
& ( \pm 0.024)^{* *}\end{aligned}$ & 0.42 & $\begin{aligned} A= & 2 \cdot 06-\mathrm{I} \cdot 703 f^{* *} \\
& ( \pm 0.534)\end{aligned}$ & 0.42 \\
\hline AII & 15 & $I \cdot 84$ & $\begin{aligned} A= & 1.78-0.004 x \\
& ( \pm 0.037) \mathrm{NS}\end{aligned}$ & 0.87 & $\begin{aligned} A= & 1.89-0.085 f \\
& \left( \pm 0.76_{5}\right) \mathrm{NS}\end{aligned}$ & 0.70 \\
\hline LII & 18 & $4 \cdot 86$ & $\begin{aligned} A= & 9.98-0.551 x \\
& ( \pm 0.144)^{* *}\end{aligned}$ & $2 \cdot 67$ & $\begin{aligned} A= & 9.99-9.944 f \\
& ( \pm 2.826)^{* *}\end{aligned}$ & $2 \cdot 79$ \\
\hline
\end{tabular}

\section{Estimation of the absorptive capacity of the small intestine for glucose}

The area beneath each individual curve relating glucose absorption in $\mathrm{m}-\mathrm{moles} / \mathrm{m} . \mathrm{h}$ with distance from the pylorus was estimated by summing successive areas on graph paper. The final value approximates to the amount of glucose that could have 
been absorbed from the intestine if it had been filled uniformly with the same test solution that was used in individual loops (Fig. 5). Absorptive capacity of the small intestine of lambs decreased during the first 3 weeks of age from $99 \mathrm{~m}$-moles $/ \mathrm{h}$ at birth to a mean rate of $37 \mathrm{~m}$-moles/h. After 3 weeks, absorptive capacity for glucose tended to increase slowly then to decrease to $22 \mathrm{~m}$-moles/h in adult sheep in the grazing group AI.

In the group given reconstituted milk (group LII) the mean absorptive capacity for glucose was $92 \mathrm{~m}$-moles/h (range $83-\mathrm{II} 3$ ); these values were greater than the

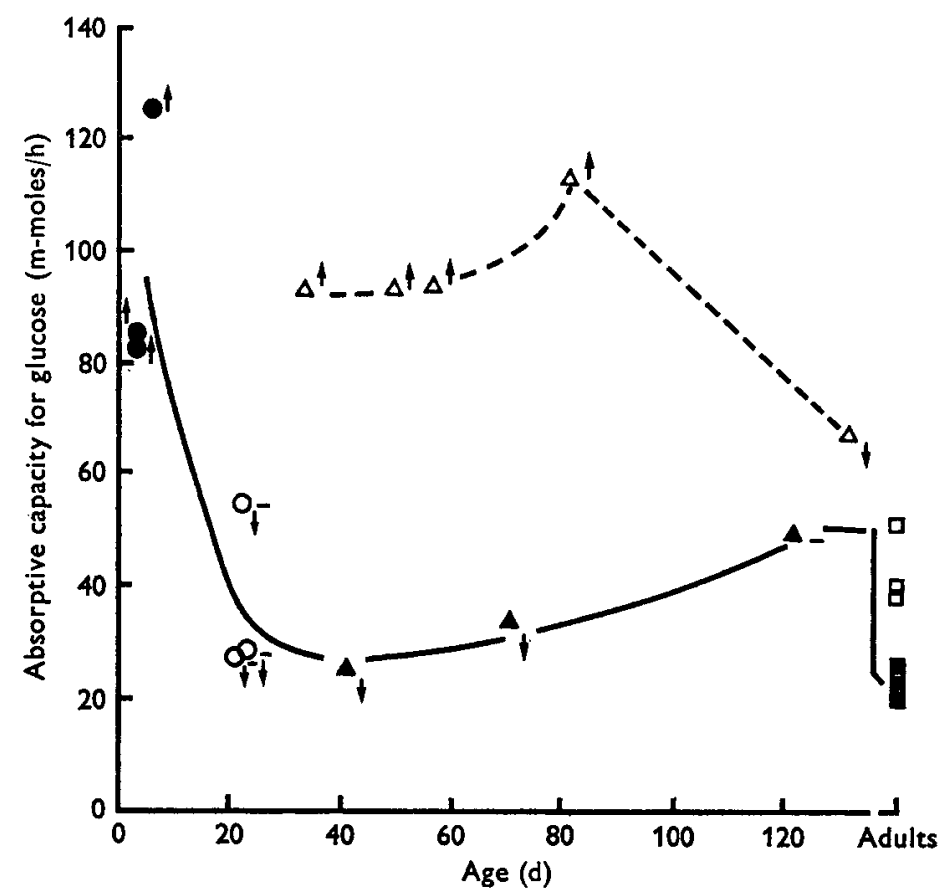

Fig. 5. Postnatal changes in the absorption capacity of the small intestine of sheep and lambs. The absorption rate was based on first order kinetics. LI $c$; $\boldsymbol{n}$, group AI; $\square$, group AII; $\triangle$, group LII. $\uparrow$, increasing level of lactose ingestion; $\downarrow$, decreasing level of lactose ingestion; - , static level of lactose ingestion.

Table r. Comparison of absorptive rates of the small intestines of sheep and lambs for glucose

(Mean values with their standard errors; rates were calculated assuming either first order kinetics (A) or zero order kinetics (B))

\begin{tabular}{|c|c|c|c|c|}
\hline \multirow[b]{2}{*}{ Group } & \multirow[b]{2}{*}{ Age and diet } & \multirow{2}{*}{$\begin{array}{l}\text { No. of } \\
\text { animals }\end{array}$} & \multicolumn{2}{|c|}{ Absorptive rate (m-moles $/ \mathrm{h})$} \\
\hline & & & $\mathbf{A}$ & B \\
\hline LIa & $2-7 d$ & 3 & $95 \pm 9.9$ & $22 \pm 3.4$ \\
\hline L I $b$ & 3 weeks & 3 & $37 \pm 8 \cdot 8$ & $19 \pm 3 \cdot 1$ \\
\hline $\mathrm{L} \mathbf{I} c$ & $5-x 7$ weeks & 3 & $3^{6} \pm 7 \cdot 3$ & $24 \pm 4.8$ \\
\hline AI & Adult; grazing & 3 & $21 \pm 0.3$ & $19 \pm 3 \cdot 2$ \\
\hline A II & $\begin{array}{l}\text { Adult; wheat }+ \\
\text { lucerne chaff }\end{array}$ & 3 & $43 \pm 4 \cdot 2$ & $30 \pm 4.7$ \\
\hline LII & 5-17 weeks; milk & 4 & $92 \pm 7 \cdot 2$ & $48 \pm 7 \cdot 2$ \\
\hline
\end{tabular}


mean glucose absorptive capacity of $36 \mathrm{~m}$-moles/h (range 25-50) in lambs of the same age groups of $5^{-1} 7$ weeks taken from their dams at pasture (group LIc) but were equal to the absorptive capacity of lambs of less than I week of age (group LIa).

Table I shows a comparison of the absorptive capacities in the various groups based on either first or zero order kinetics. A clear discrepancy between the two methods of estimating glucose absorption was noted in lamb groups LI $a, \mathrm{LI} b$ and LII. The discrepancy was less for lamb group LI $c$ and adult group A II and there was no difference for adult group AI.

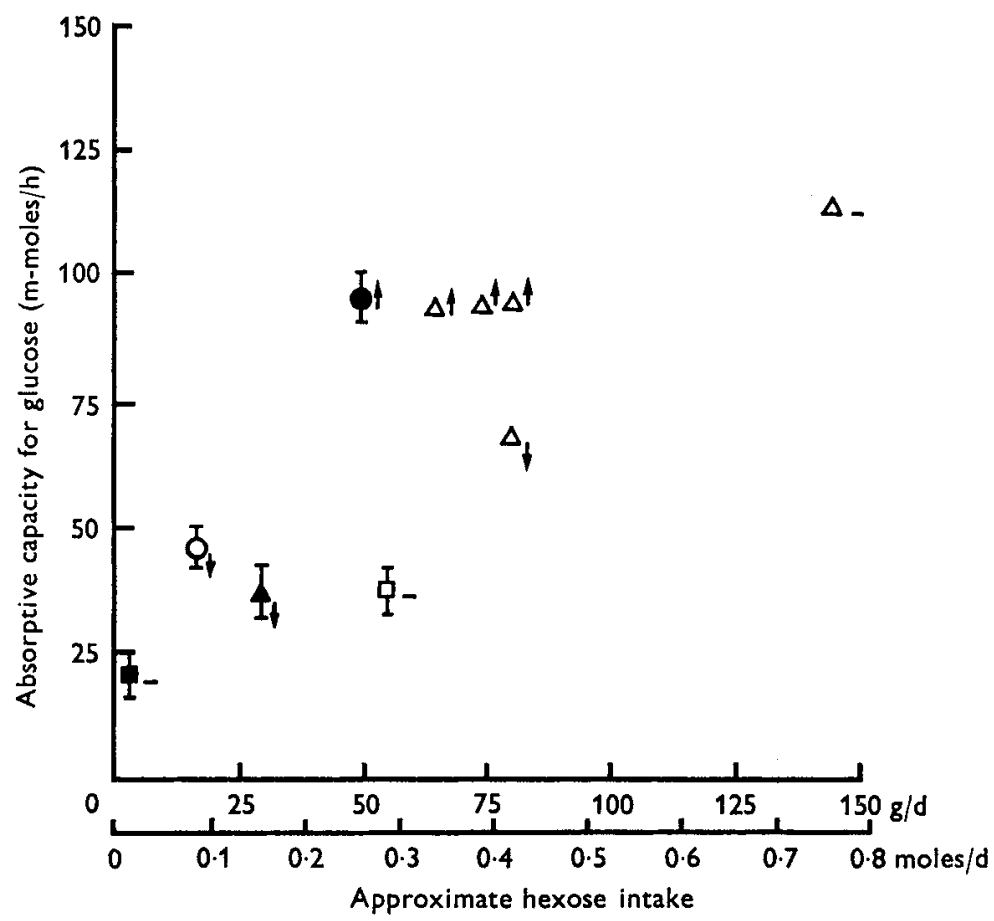

Fig. 6. The relationship between actual or estimated hexose intakes and the absorptive capacity of the small intestine of sheep and lambs for glucose, based on first order kinetics. , group LI $a ; O$, group $\mathrm{LI} b ; \Delta$, group LI $c ; \Delta$, group LII; $\square$, group AI; $\square$, group A II; $\uparrow$, increasing level of hexose ingestion; $\downarrow$, decreasing level of hexose ingestion; - , static level of hexose ingestion. The vertical line through the symbol represents \pm one SD of the mean.

\section{Effect of hexose intake on the absorptive capacity for glucose}

The milk intake of lambs in the grazing groups was not measured, but an estimate of lactose intake was made by using values for milk intake for Merino lambs obtained by Davies ( 1963$)$ and a lactose concentration of $5.0 \mathrm{~g} \%(\mathrm{w} / \mathrm{v})$ obtained by Corbett (I968). Fig. 6 shows the estimated values for lactose intake in relation to mean glucose absorptive capacity based on first order kinetics. The relationship between glucose absorptive capacity and lactose intake appears to be close in groups L $a, b$ and $c$, but not in group LII. In group LII a large part of the variability may have been due to the increasing lactose intake during the experimental period. In all instances the absorptive 


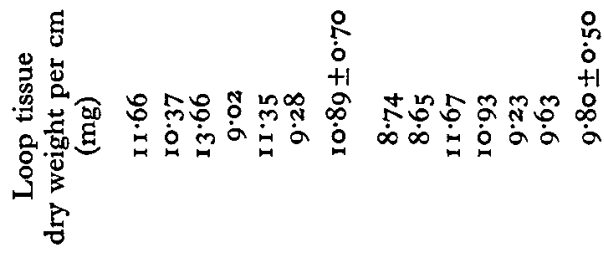

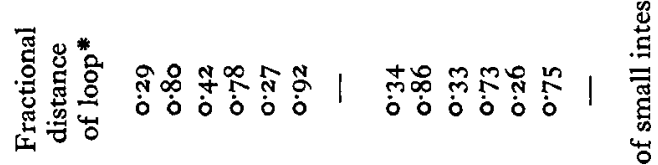

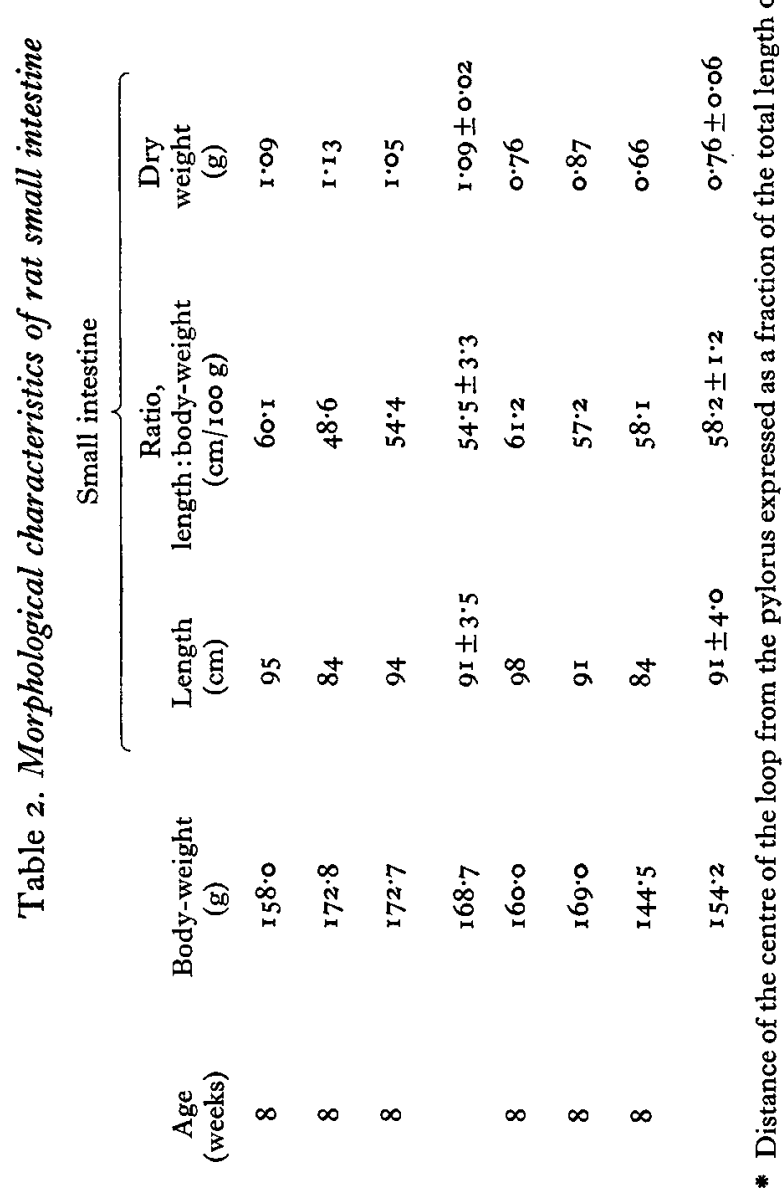

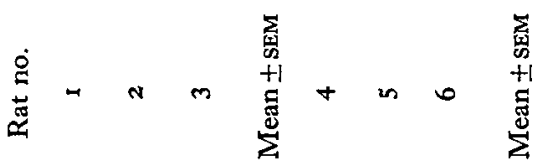


potential for glucose was higher when the daily intake of lactose was increasing than when the intake was expected to be decreasing.

The results for the two adult groups are also shown. The approximate quantity of hexose entering the small intestine was taken as $\mathrm{I}-5 \mathrm{~g} / \mathrm{d}$ from values for sheep given roughage, in which the origin of hexose is mainly bacterial (Heald, I951) and 16.8$21.9 \mathrm{~g} / \mathrm{d}$ of $\alpha$-linked glucose polymers for sheep given grain rations similar to those in this study (MacRae \& Armstrong, 1966).

\section{Rats}

Some morphological characteristics of the small intestine of the two groups of rats used in the absorption studies are listed in Table 2. Both groups of rats were of similar body-weight. There was no significant difference in mean length of small intestine per unit body-weight.

Table 3. Comparison of mean rates with their standard errors of disappearance of glucose from ligated loops of small intestine in adult rats and sheep

(Rates were calculated assuming either first order kinetics (A) or zero kinetics (B))

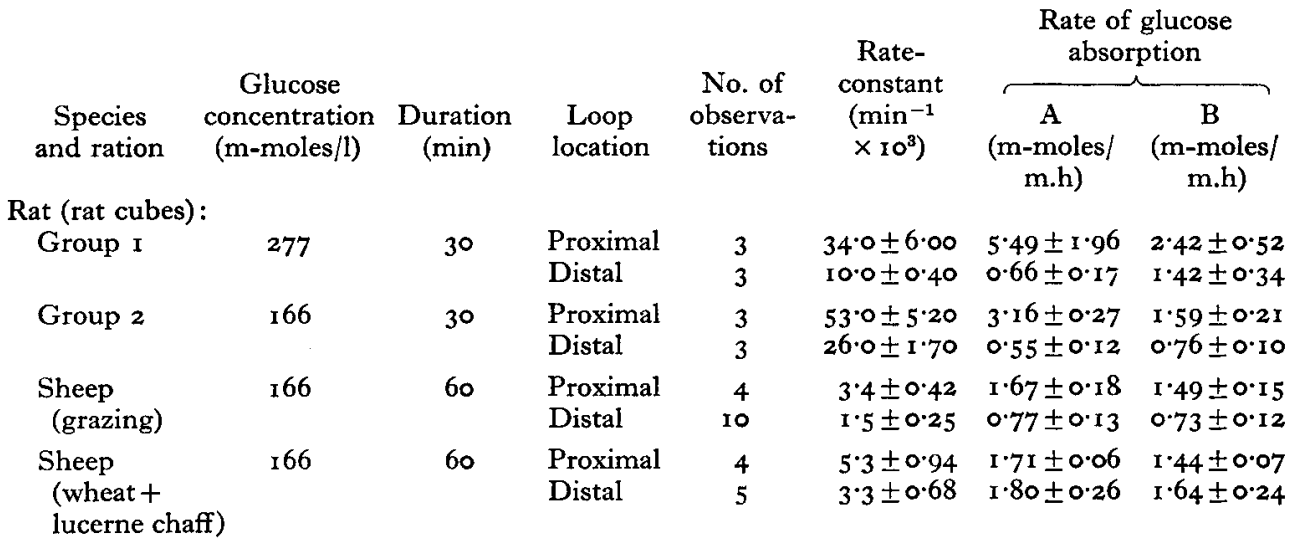

The results for glucose absorption from the small intestine are shown in 'Table 3 . Values for the glucose concentration in the saline-filled loops are not shown, but it was less than $0.09 \mathrm{~m}$-moles/ 1 at the end of each absorption period. The glucose concentration in the blood of rats would be approximately forty times greater than this, showing that the amount of glucose transported from blood to lumen was very small (0.01 m-moles) compared with the amount absorbed (0.27-8.7 m-moles).

In group I, a $277 \mathrm{~m}$-molar solution of glucose, and in group 2 a $166 \mathrm{~m}$-molar solution, was injected into each loop of small intestine. The results for a $30 \mathrm{~min}$ experimental period are shown in Table 3. In all the experiments the amount of glucose remaining at the end of each period was more than $10 \%$ of the amount injected.

The rates of absorption of glucose were calculated assuming first order kinetics and zero order kinetics. The rate of glucose absorption was expressed as a function of a unit length of small intestine. The rate of absorption from the higher glucose concentration of $277 \mathrm{~m}$-moles/l was faster than from the concentration of $166 \mathrm{~m}$-moles/l. 


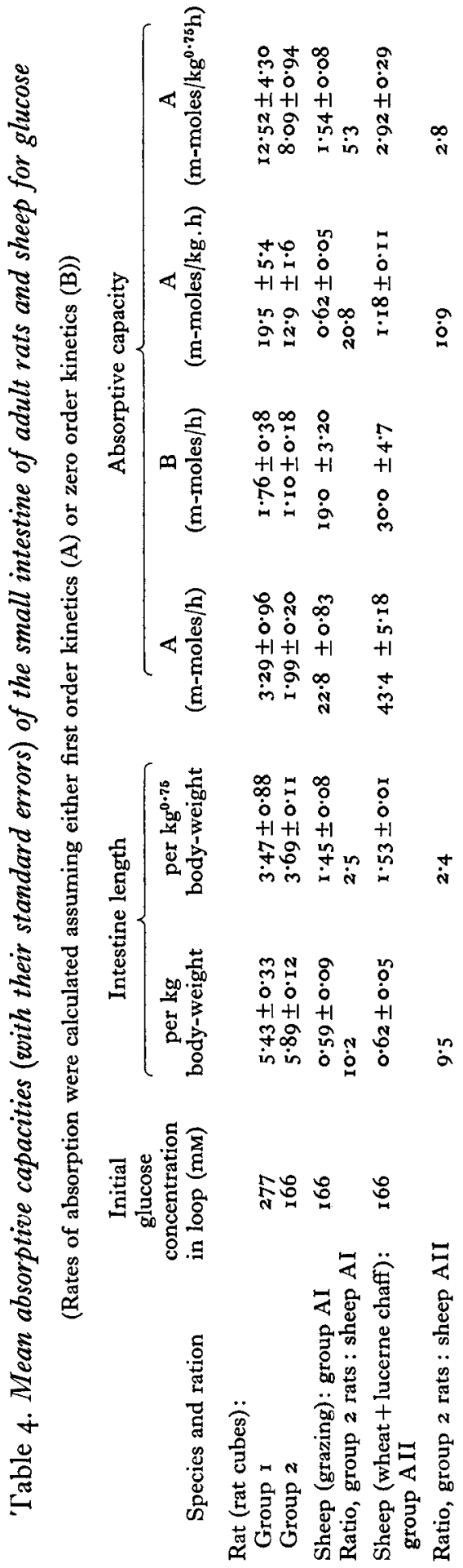


In both groups of animals the same general trends in glucose absorption within the intestine were noted. The mean rate-constants and mean rates of glucose absorption were greater from the proximal than from the distal half of the small intestine. Because the loops of intestine were large relative to the total length of small intestine (approximately $20 \%$ ), the 'local' absorption rates of a number of sites could not be measured. Hence, it was not possible to assess the shape of the curve relating the rate of absorption of glucose with loop position in the rat.

Table 3 also shows the mean absorption rates of glucose measured in the two groups of adult sheep. The absorption rate from a $166 \mathrm{~mm}$-solution based on first order kinetics and expressed as a function of loop length (m-moles $/ \mathrm{m} . \mathrm{h})$ was $90 \%$ greater in the jejunum of rats than in that of sheep; there was little difference in the ileum even though the rate-constants from loops in the sheep were less than one-tenth of those in rats. In adult sheep given wheat plus lucerne hay the absorption rate from the jejunum was $85 \%$ less than from the jejunum of rats, but the absorption rate from the ileum of sheep in this group was three times that for rat ileum.

The absorptive capacity for glucose of the total length of small intestine was estimated by measuring the area beneath a line, drawn by eye, through the peaks of a histogram of absorption rate in $\mathrm{m}$-moles $/ \mathrm{m} . \mathrm{h}$ and the distance $(\mathrm{m})$ of the centre of the loop from the pylorus. The estimate for each rat is listed in Table 4. The mean capacity for glucose absorption from the $277 \mathrm{~mm}$-solution was greater than that from the $166 \mathrm{~mm}$-solution when the calculation of absorption rate was based on first and zero order kinetics.

Table 4 also shows the mean absorptive capacities of the two adult groups of sheep. A I $66 \mathrm{~mm}$-glucose solution was used in the sheep so that results for them are comparable with those for the rats in group 2. Allowing for the differences in body size by expressing absorptive capacity as $\mathrm{m}$-moles $/ \mathrm{kg} . \mathrm{h}$, the rates of absorption were respectively 10.9 and 7.1 times greater in rats than in adult sheep given wheat plus lucerne hay (group A II) for first order and zero order kinetics. The ratio was much greater in the comparison of the rats with grazing sheep (group AI), being 20.8 and I 3.1 for the first and zero order calculations respectively. When the results based on first order kinetics were expressed as $\mathrm{m}$-moles $/ \mathrm{kg}^{0 \cdot 75} . \mathrm{h}$, the ratio for group A II was $2 \cdot 8$ and for group AI, $5 \cdot 3$.

\section{DISCUSSION}

Although there have been several experiments designed to assess the amount of glucose reaching and absorbed by the small intestine of grazing sheep (Heald, I95I; McClymont \& Scarisbrick (cited by McClymont, 195I); Schambye, I95 I $a, b$; Weller \& Gray, 1954) and sheep given diets high in grain (MacRae \& Armstrong, I 966, I969; Ørskov et al. 1969; Nicholson \& Sutton 1969), there are apparently no studies on the ability of the small intestine of sheep to absorb glucose. Such studies must be made to establish the ability of the small intestine to absorb glucose by active and passive transport mechanisms and to assess the potential of the active and passive transport mechanisms to become adapted to changes in the diet of the animal. With increasing intensity of lamb production there has been a renewed interest in establishing the 
potential growth rate and efficiency of growth. Expensive artificial rations high in digestible carbohydrate and protein would largely need to by-pass rumen fermentation, with almost all the ingested nutrients being digested and absorbed by the small intestine, to effect a maximum rate of conversion of feed into body constituents. Hence, one potential limit to conversion ratios is set by the ability of the small intestine to absorb hexoses. Walker \& Faichney (1964) suggest that scouring in young lambs may be caused by ingestion of hexose in excess of $10 \mathrm{~g} / \mathrm{kg}$ body-weight per $\mathrm{d}$, which indicates possible limitation in the use of such foodstuffs. In the present study the ability of the small intestine of lambs and sheep to absorb glucose has been examined. Undoubtedly, glucose is absorbed by passive and active transport, but it has not been possible to assess from this work the contribution each mechanism makes to glucose absorption.

In general, lambs given the reconstituted-milk diet grew slightly more slowly than their controls at pasture. However, these variations in growth rate did not greatly affect the relationship between length of small intestine and body-weight (Fig. I). Fig. I shows that the small intestine reaches adult proportions at approximately $17 \mathrm{~kg}$ body-weight, which in this study was reached by $50 \mathrm{~d}$ of age. Since this is around the minimal age at which lambs are usually weaned, it is clear that the small intestine has developed fully in length and weight in time for this dietary change.

Before the rate of absorption can be estimated routinely, the kinetics of the absorptive process must be known. Fig. 2 shows that in 3-week-old lambs and adult sheep the process appeared to be almost entirely explained by first order kinetics, although there also appeared to be some other effect which suggested a slight approximation to second order kinetics in one of the studies (Fig. 2c).

In most studies on the absorption of glucose from ligated loops of intestine zero order kinetics have been assumed, generally without sufficient evidence to show that the duration of the experiment was sufficiently short to approximate a constant rate of glucose absorption over the whole period. For comparison with these previous reports, the rate of glucose absorption has also been calculated assuming zero order kinetics. Table 3 shows the comparison of the rates of absorption based on first and zero order kinetics in sheep and rats, and Table 4 shows estimates of the capacity of the whole intestine to absorb glucose. As would be expected, approximation to zero order kinetics resulted in a gross underestimation of the rate of absorption in all the animals in which the potential to absorb glucose was very high (i.e. most lambs from groups LI and LII, Table 4).

The evidence for a first order process supports the observation on rabbits by Bárány \& Sperber (r 94I) that at least one part of the mechanism of absorption of glucose is a process of passive diffusion from media containing high concentrations of glucose. Bárány \& Sperber (194I) expressed the absorption rate $(A R)$ in $\mathrm{mg} / \mathrm{cm}$ length per $30 \mathrm{~min}$ by the equation

$$
A R=26 \cdot 3+3 \cdot 76 C( \pm \mathrm{I} \cdot 84),
$$

where $C$ is the glucose concentration $(\mathrm{mg} / \mathrm{ro0} \mathrm{ml})$. The authors suggested that the constant term of this expression, $26.3 \mathrm{mg} / \mathrm{min}$. $\mathrm{cm}(0 \cdot 88 \mathrm{~m}$-moles $/ \mathrm{m}$. h), was ' . . cor- 
related with active absorption'. In sheep, the importance of active transport relative to passive transport of glucose is not known.

Rate-constants (Fig. 3) and the rates of absorption of glucose (m-moles/m.h), calculated assuming either zero or first order kinetics, were significantly higher in the proximal jejunal region than in the ileal region of lambs in groups LI $a, b$ and $c$, in group LII and in adult sheep at pasture (group AI). Similar trends have been noted for several other species including the dog (Reid, I900; Magee \& Reid, I93I; Annegers, 1964), the rat (Fisher \& Parsons, 1950) and man (Cummins \& Jussila, I955). The same trend was also noted when absorption rate was expressed as a function of the dry weight of the small intestine (m-moles/g.h).

The exponential decrease in rate-constants and the rectilinear decrease in the rate of glucose absorption from the pylorus to the ileocaecal valve are probably functions of surface area; a decrease in the mucosal surface area per unit length along the intestine has been noted in the dog (Warren, 1939), cat (Wood, 1944) and rat (Fisher \& Parsons, 1950). Fisher \& Parsons showed that, whereas glucose was metabolized at the same rate at all sites by the intestinal wall of the rat, there was a gradient of absorption from the jejunum to the ileum.

The decrease in the rate of glucose absorption calculated by first order kinetics (m-moles/m.h) in these studies was mainly due to the faster rate-constant in the upper compared with the lower intestine (Fig. 3). In fact, the gradient in absorptive function with distance from the pylorus was less than expected from the rate-constants in Fig. 3. Absorption rates based on first order kinetics are a function of the amount of glucose injected and the rate-constant, equation (3), and in rats, lambs and adult sheep the amount of glucose injected into loops of intestine in the ileum was generally greater than that injected into loops of intestine of comparable length in the jejunum.

Conformity of absorption to first-order kinetics (Fig. 2) shows that the rate of absorption is in direct proportion to the concentration of the solute provided that the volume of test solution is constant; the proportionality constant reflects barriers to absorption in the form of surface area or limiting membranes (Wilbrandt \& Rosenberg, I96I). There was no attempt to correlate rate-constants with surface area for lambs and sheep in this study.

With a diet high in wheat it was expected that some grain would escape fermentation in the rumen and would then be a source of glucose for absorption from the small intestine. It has been shown that at least a small quantity of glucose may be available for absorption from the small intestine of sheep given high-starch diets (MacRae \& Armstrong, I966, I969; Topps, Kay \& Goodall, I968; Ørskov et al. I969; Nicholson $\&$ Sutton, I969). MacRae \& Armstrong ( I 966 ) have estimated that between I6.8 and $21.9 \mathrm{~g} / \mathrm{d}$ of $\alpha$-linked polymers of glucose enter the small intestine of sheep given $200 \mathrm{~g}$ hay plus $700 \mathrm{~g}$ rolled barley/d. Since the quantity of starch eaten by the adult sheep in our high-grain group A II was similar to the quantity MacRae \& Armstrong (I966) fed to their animals, it is probable that some glucose was absorbed from the small intestine. This may have caused a detectable adaptation to diet. Apparent adaptation was confined to the distal half of the small intestine (Table 3 ; Fig. ${ }_{4} \mathrm{D}$ and $\mathrm{F}$ ). 
The increased ability of the small intestine in lambs on high lactose intakes to absorb glucose may have been due to adaptation at the cellular level or to increased surface area, particularly in the mid-portion of the intestine (Fig. $4 \mathrm{D}, \mathrm{F}$ ). The total absorptive capacities of the milk-fed lambs were not closely related to age (Fig. 5) or daily lactose ingestion (Fig. 6). When the regression was extended to include absorptive capacity of adult sheep and lambs from group LI the trend in absorptive capacity with daily hexose intake was clear (Fig. 6). This suggests a possible regulatory effect of dietary hexose on the capacity for glucose absorption of the small intestine of the sheep. However, closer examination indicates that the relationship may have been fortuitous, as large differences in absorptive capacity were noted when daily lactose intake was tending to increase or decrease in the period before the experiment.

In calves, the small intestine responds to high lactose intakes by increases in lactase activity due to hypertrophy of the mucosal tissue, the specific activity of lactase being apparently unaffected by the high substrate concentration (Huber, Rifkin \& Keith, 1964). Hypertrophy of mucosal tissue (White, 1967) and increase in weight of the jejunum in response to high lactose intake were noted in lambs given the reconstituted milk in this study, suggesting a similarity in adaptation to hexose intake in lambs and calves.

One possible criticism of this work is that the test solution contained too high a concentration of glucose. The recent findings of Mylrea (1966) would not substantiate this criticism for non-weaned lambs, as he found the concentration of reducing substances in duodenal fluid after giving milk to young calves to be between $\mathrm{I} \cdot \mathrm{O}$ and

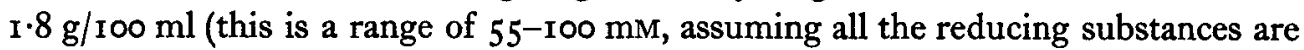
hexoses). The concentration at the site of hydrolysis may be even greater. No similar studies on lambs have been found in the literature. The concentration of lactose entering the small intestine is probably similar to that in calves, since the lactose concentration of Merino ewe's milk $(4 \cdot 3-4 \cdot 8 \mathrm{~g} / \mathrm{100} \mathrm{ml}$, Pierce, $1934 ; 5 \cdot 35-5 \cdot 74 \mathrm{~g} /-$ roo ml, Corbett, I968) is similar to that reported by Mylrea (1966) for cow's milk, if $2.3 \mathrm{~g} / \mathrm{ro0} \mathrm{ml} \mathrm{glucose}$ equivalent can be equated to approximately $4.3 \mathrm{~g} / 100 \mathrm{ml}$ of lactose. Fully to compare lambs and adult sheep, however, further studies are required to measure the relative capacities for active glucose absorption in different parts of the intestine, since this mechanism is probably the only one functioning in adults.

The between-species comparisons of the absorptive function of the small intestine for glucose show that the rate of glucose absorption per unit length in the rat was on average about $50 \%$ greater than that for the adult sheep (Table 3). However, the absorptive capacity of the small intestine per $\mathrm{kg}$ body-weight ${ }^{0.75}$ based on first order kinetics was 5.3 times greater in the rat than in grazing sheep, and 2.8 times greater than in sheep given wheat and lucerne chaff (Table 4). Therefore, these differences must be largely due to variations in the length of the small intestine per kg bodyweight (Table 4).

There are few studies relating development of the small intestine to changes in the rate of glucose absorption. Koldovský and his associates (Koldovský, Hahn \& Jiránek, 1958; Koldovský, Faltová, Hahn \& Vacek, I96r ; Faltová, Hahn \& Koldovský, 1962) investigated developmental changes in the rat in detail and suggested that the differ- 
ence in absorptive capacity for glucose expressed as a function of body-weight ( $\mathrm{mg} / 100 \mathrm{~g}$ per $30 \mathrm{~min}$ ) '... can be correlated with changes in quantity and quality of food eaten...' (Faltová et al. I962) as the absorptive capacity and carbohydrate intake increased in parallel from birth to weaning. After weaning, the absorptive capacity decreased and in adults was one-third of the capacity at weaning. The absorptive capacity was also affected by the adrenocortical system but the biological importance of the system as a regulator of absorptive capacity was not defined.

The glucose concentration used by Faltová et al. (I962) was $5 \%(\mathrm{w} / \mathrm{v})$, which was similar to solutions injected into the loops of rats 8 to 9 weeks old in group $I$ of this study. The absorptive capacity of the adult animals reported by Faltová and coworkers was based on zero order kinetics and was $105 \mathrm{mg} / 100 \mathrm{~g}$ body-weight per $30 \mathrm{~min}$; this rate was similar to the zero order rate $(10.3 \mathrm{~m}$-moles $/ \mathrm{kg}$.h or $93 \mathrm{mg} /-$ roo g.min) obtained by us (Table 4 ).

Evidence from sheep in this study agrees with the observations for rats (Koldovsky et al. I961; Faltova et al. 1962) that the ingested quantity of dietary precursors of glucose alters the absorptive characteristics of the small intestine for glucose. In the young lamb, the quantity of lactose ingested can affect the absorptive capacity of the small intestine for glucose. However, after weaning, grazing sheep absorb very little glucose and the absorptive rates and absorptive capacities reported for the adult grazing sheep (group AI) may be minimal for each animal.

We thank Miss N. Todd and Messrs R. Kenny, J. Sheedy and M. Inskip for technical assistance. This work was assisted by research grants from the University of New England and the Australian Wool Board.

\section{REFERENCES}

Annegers, J. H. (1964). Am. F. Physiol. 206, 1095.

Bárány, E. \& Sperber, E. (1941). Ark. Zool. 34, r.

Corbett, J. L. (1968). Aust. F. agric. Res. 19, 283.

Cummins, A. J. \& Jussila, R. (1955). Gastroenterology 29, 982.

Davies, H. L. (1963). Aust. F. agric. Res. 14, 824.

Faltová, E., Hahn, P. \& Koldovský, O. (1962). (Fiziol. Zh. SSSR 48) Fedn Proc. Fedn Am. Socs exp. Biol. (Trans. Suppl.) 22, T 941 .

Fisher, R. B. \& Parsons, D. S. (1950). F. Anat. 84, 272.

Heald, P. J. (195I). Br. F. Nutr. 5, 84 .

Huber, J. T., Rifkin, R. J. \& Keith, J. M. (1964). F. Dairy Sci. 47, 789.

Huggett, A. St G. \& Nixon, D. A. (1956). Biochem. F. 66, 12 P.

Koldovský, O., Faltová, E., Hahn, P. \& Vacek, Z. (1961). In The Development of Homeostasis p. I55. Symposium Chairman, E. F. Adolf. Publishing House, Czechoslovak Acad. Sci. Prague.

Koldovský, O., Hahn, P. \& Jiránek, J. (1958). Cslká Physiol. 17, 491. Quoted by Koldovský et al. (r96r).

MacRae, J. C. \& Armstrong, D. G. (I966). Proc. Nutr. Soc. 25, xxxiii.

MacRae, J. C. \& Armstrong, D. G. (1969). Br. Y. Nutr. 23, 377.

McClymont, G. L. (195I). Aust. F. agric. Res. 2, 92.

Magee, H. E. \& Reid, E. (193I). F. Physiol., Lond. 73, 163.

Mylrea, P. J. ( I966). Res. vet. Sci. 7, 394.

Nicholson, J. W. G. \& Sutton, J. D. (1969). Br. F. Nutr. 23, 585.

Ørskov, E. R., Frazer, C. \& Kay, R. N. B. (1969). Br. F. Nutr. 23, 217.

Pierce, A. W. (1934). Aust. F. exp. Biol. med. Sci. 12, 7.

Reid, E. W. (1900). Phil. Trans. R. Soc. B 192, 21 I.

Schambye, P. (I95 I $a$ ). Nord. VetMed. 3, 555. 
Schambye, P. (195 $\mathrm{I} b)$. Nord. VetMed. 3, 748.

Snedecor, G. W. (1956). Statistical Methods. Ames, Iowa: Iowa State College Press.

Topps, J. H., Kay, R. N. B. \& Goodall, E. D. (1968). Br. F. Nutr. 22, 26r.

Walker, D. M. \& Faichney, G. J. (1964). Br. F. Nutr. 18, 209.

Warren, R. (1939). Anat. Rec. 75, 427.

Weller, R. A. \& Gray, F. V. (1954). F. exp. Biol. 3r, 40.

White, R. G. (1967). Absorption of glucose from the small intestine of sheep. M Rur Sc. Thesis, University of New England, Australia.

Wilbrandt, W. \& Rosenberg, T. (I96r). Pharmac. Rev. 13, 109.

Wood, H. O. (1944). F. Anat. 78, 103. 